\section{Física del organismo vs hermenéutica del viviente: el alcance del programa reduccionista en la biología contemporánea}

\section{Physics of organisms versus hermeneutics of living being: the reach of the reductionist program in contemporary biology}

CAPONI, Gustavo. Física del organismo vs hermenéutica del viviente: el alcance del programa reduccionista en la biología contemporánea. História, Ciencias, Saúde - Manguinhos, Rio de Janeiro, v.14, n.2, p.443-468, abr.-jun. 2007.

La distinción entre biología funcional y biología evolutiva, conforme la plantearon E. Mayr y F. Jacob, es clave para un tratamiento conclusivo de uno de los más discutidos problemas de la filosofía de la biología: la posible reducción de la biología a física y química. Las preguntas que definen los objetivos cognitivos de la biología funcional son diferentes de aquellas que guían la física: son preguntas funcionales; pero las respuestas que buscamos para ellas pueden escribirse en el lenguaje de la física. Mientras tanto, las cuestiones planteadas en la biología evolutiva nos conducen hacia un tipo de discurso intraducible en el lenguaje de la física. Para mostrar esto analizamos los procedimientos experimentales que han sido desarrollados en genética de poblaciones.

PALABRAS-CLAVE: reduccionismo; biología evolutiva; biología funcional; Ernst Mayr; François Jacob.

CAPONI, Gustavo. Physics of organisms versus hermeneutics of living being: the reach of the reductionist program in contemporary biology. História, Ciências, Saúde - Manguinhos, Rio de Janeiro, v.14, n.2, p.443-468, Apr.-June 2007.

The distinction between functional biology and evolutionary biology, as set out by E. Mayr and F. Jacob, is central to any conclusive findings on one of the most widely discussed problems in the philosophy of biology: the possible reduction of biology to physics and chemistry. The questions that define the cognitive objectives of functional biology are different from those that guide physics: they are functional questions, but the answers we seek for them can be expressed in the language of physics. Meanwhile, the questions set forth in evolutionary biology lead to a kind of discourse that cannot be translated into the language of physics. In order to show this we analyze the experimental procedures that have been developed in population genetics.

KEYWORDS: reductionism; evolutionary biology; functional biology; Ernst Mayr; François Jacob.
Gustavo Caponi

Departamento de Filosofía - CFH Universidade Federal de Santa Catarina Caixa Postal 476 88040-900 Florianópolis - SC - Brasil caponi@cfh.ufsc.br 
T a discusión sobre la posibilidad de reducir las ciencias de la $\checkmark$ vida a la física y a la química constituye uno de los tópicos más transitados y recurrentes de la filosofía de la biología. Creemos, sin embargo, que el tratamiento de esta cuestión se ha visto en general obstaculizado y entorpecido por el hecho de que en su planteamiento no se ha prestado la debida atención a un hecho capital: nos referimos a la clásica, aunque por lo visto no siempre considerada, distinción entre biología evolutiva y biología funcional. Pasando por alto las importantes diferencias que existen entre esos dos dominios disciplinares, se ha incurrido no pocas veces en el error de contraponer tesis y argumentos pro-reduccionistas relativos a la biología funcional con tesis y argumentos antireduccionistas pertinentes a la biología evolutiva.

Siendo ese error, en nuestra opinión, lo que no ha permitido entrever una posible salida para la vieja querella sobre el reduccionismo: la misma consistiría en reconocer la validez y la pertinencia del programa reduccionista en el campo de la biología funcional, desconsiderando, al mismo tiempo, su aplicabilidad y su relevancia en el dominio de la biología evolutiva. La biología funcional, creemos, puede seguir siendo pensada como la física del ser viviente aun cuando esa caracterización en nada convenga a la biología evolutiva; y esta disciplina puede ser pensada desde un punto de vista marcadamente antireduccionista sin que eso comprometa nuestro modo de considerar a la biología funcional. Las páginas que siguen son un intento de mostrar las motivaciones y la plausibilidad de esa alternativa.

\section{Las dos biologías}

Muchos autores han llamado la atención sobre los contrastes existentes entre la biología experimental de los laboratorios, la biología de Claude Bernard y de André Lwoff, por ejemplo, y la biología observacional de campo; es decir: la biología de los naturalistas como Darwin y Niko Timbergen (Allen, 1979; Araujo, 2001; Ricqlès, 1996; Magnus, 2000). Otros, mientras tanto, se han detenido en las diferencias que existen entre un enfoque 'reduccionista' de los fenómenos vivientes y un enfoque que, usando una expresión de George Gaylord Simpson (1974, p.42), podría ser tal vez caracterizado como 'composicionista' (por ej., Pichot, 1987; Morange, 2002). Un tercer grupo, a su vez, ha subrayado la oposición y complementación entre preguntas relativas a cómo los fenómenos biológicos ocurren y preguntas relativas al por qué de los mismos (por ej., Brandon, 1990, p.167; Sober, 1993, p.8); y, entre ellos, hay quienes supieron señalar la vinculación existente entre esa distinción entre el cómo y el por qué de lo viviente y la distinción entre las causas próximas y las causas remotas de los fenómenos biológicos (por ej., Nesse, Williams, 1996, p.7; Brewer, 1994, p.29). 
Ha sido, sin embargo, mérito de Ernst Mayr (1988) el insistir sobre la posibilidad y la relevancia epistemológica de articular, hasta cierto punto, todas estas distinciones insertándolas en el marco de una contraposición más general entre esos dos vastos dominios de indagación científica que serían la biología funcional y la biología evolutiva. La primera sería aquella biología que, siguiendo procedimientos experimentales semejantes a los de la química y la física, se ocupa del estudio de las causas próximas que, actuando a nivel del organismo individual, nos explican cómo los fenómenos vitales se encadenan e integran en la constitución de esas estructuras. La segunda, mientras tanto, sería esa otra biología ocupada en indagar, recurriendo, básica pero no exclusivamente, a evidencia observacional, a métodos comparativos y a inferencias históricas, las causas remotas que, actuando a nivel de las poblaciones, nos explicarían por qué éstas evolucionan o evolucionaron en el modo en el que efectivamente lo hacen y lo hicieron.

Pero, en nuestra opinión, el modo más adecuado de entender la diferencia que existe entre estos dos dominios de investigación es ensayar una contraposición entre los dos diferentes tipos de preguntas que, según Mayr, los biólogos pueden plantearse en relación a cualquier fenómeno biológico. Así, si pensamos en una estructura tan simple o elemental como una secuencia de ADN, llamémosla 'gen', cuya ocurrencia se verifique en el genoma de alguna cepa de bacterias, veremos que la misma puede suscitarnos dos líneas diferentes, aunque complementarias, de interrogación. Una primera línea de interrogación podría ser aquella que suscita la pregunta por la expresión funcional de esa secuencia: querremos saber cuál es la proteína codificada por ese gen; $y$, si damos con una respuesta para esta pregunta, podremos ir un poco más lejos y preguntarnos por cuál es el papel causal o función que esa proteína tiene en el funcionamiento de cada uno de tales organismos. Así, si tenemos éxito en nuestro trabajo, sabremos cómo es que ese gen y la proteína por él codificada intervienen y se integran en la trama de causas próximas que materializan la autopoiesis celular.

Pero supongamos que una vez establecida tanto la función del gen, cuanto la función de 'su proteína', verificamos no sólo que el mismo presenta una alta tasa de mutación y que esas mutaciones pueden abortar la división celular impidiendo la reproducción de nuestras bacterias; sino que también verificamos que esa función es cumplida en otra cepa de bacterias de la cual la nuestra deriva, pero que se desarrolla en un hábitat diferente por un gen muy semejante, pero ligeramente distinto, que no presenta ese riesgo de mutación: ¿No querríamos saber, en ese caso, el por qué de esa diferencia? ¿No querríamos saber por qué lo que se puede hacer sin correr cierto riesgo es hecho corriéndolo? 
Ingresaríamos así en el estudio de las causas remotas y lo haríamos formulando preguntas para las que no se carece de posibles respuestas. La teoría de la selección natural lleva a los biólogos a pensar que, bajo el despiadado imperio de la lucha por la existencia, no hay riesgo que se contraiga si el hecho de contraerlo no comporta alguna ventaja o no es el costo residual de haber contraído tal ventaja (Cronin, 1991, p.67); y a partir de ahí pueden surgir diferentes hipótesis testables. Algunas podrían apuntar, si fuese el caso, que ese gen realiza esa función a un costo energético menor que su variante más segura y que ese es todo el costo que, por su metabolismo o por los recursos disponibles en su ambiente, nuestra bacteria puede sostener.

Esa misma hipótesis, a su vez, puede tener una variante que no aluda a los recursos actualmente disponibles sino a los recursos disponibles en un hábitat primitivo que habría moldeado el metabolismo de nuestras bacterias. Otras conjeturas, sin embargo, pueden referirse a las ventajas selectivas que comportaría una alta tasa de variabilidad en bacterias condenadas a proliferar en ambientes cambiantes, aun cuando esa variabilidad suponga también la posibilidad de mutaciones letales. Así, para irritación de los detractores de la fértil e inagotable imaginación darwinista, podríamos seguir elucubrando hipótesis que luego, claro, deberían ser testadas. Lo que importa ahora, sin embargo, no es discutir las dificultades y las consecuencias de esos posibles tests de las narraciones adaptacionistas, sino percibir las diferencias que existen entre las preguntas que tales historias responden y las preguntas a las que responderían los análisis funcionales del gen como los referidos en primer lugar. O como lo explica Ernst Mayr (1998b, p.136):

Una cierta molécula tiene un papel funcional en un organismo. ¿Cómo desempeña esa función, cómo interactúa con otras moléculas, cuál es su papel en el equilibrio energético de la célula etc.?...Estas preguntas representan un estudio de las causas próximas. Pero, si nos preguntamos por qué la célula contiene esa molécula, qué papel desempeñó en la historia de la vida, cómo puede haber cambiado durante la evolución, en qué y por qué difiere de moléculas homólogas en otros organismos, y preguntas similares, estamos tratando con causas últimas.

Podemos decir, por eso, que mientras las causas próximas, que actúan en el plano molecular, explican cómo se realiza o decodifica el programa contenido en el DNA; las causas remotas, que actúan en el plano poblacional, nos explican por qué el programa genético que habrá de realizarse en cada organismo individual acabó siendo del modo en que efectivamente es (Mayr, 1988, p.27; 1998b, p.137). Lo importante aquí, sin embargo, es no perder de vista que esta dualidad no sólo alcanza a fenómenos que tengan directamente 
que ver con la estructura molecular de los organismos: la misma puede también ser apuntada en el estudio de fenómenos biológicos mucho más complejos.

Un caso posible sería el análisis de un padrón comportamental característico de alguna especie. Así el comportamiento de ciertas aves insectívoras de zonas templadas que en otoño migran a regiones tropicales o subtropicales puede ser explicado como consecuencia de un proceso evolutivo de millares o millones de años vinculado con la disponibilidad de alimentos (Mayr, 1998a, p.88); y la reconstrucción de esos factores históricos nos revelará las causas remotas del ciclo migratorio de esa especie: su por qué. Pero si queremos saber cómo, por la mediación de qué dispositivo, cada ejemplar de una especie de ave migratoria sabe cuándo comenzar su jornada, y cómo orientarla, deberemos realizar un estudio neurofisiológico de las causas próximas de esa conducta (Mayr, 1998b, p.136).

Conforme lo apuntaba François Jacob (1973) en su Lógica de lo viviente, cada una de estas biologías aspira a instaurar un diferente tipo de orden en el mundo viviente: en el caso de la biología evolutiva, "se trata del orden por el que se ligan los seres, se establecen las filiaciones, se diseñan las especies" (p.16); y en el caso de la biología funcional, se trata de ese orden intra-orgánico que atañe a las estructuras, funciones y actividades por medio de las cuales se integra y se constituye el viviente individual. Puede decirse, entonces, que mientras la primera "considera a los seres vivos como elementos de un vasto sistema que engloba toda la tierra"; la otra "se interesa por el sistema que forma cada ser vivo" (p.16). Por eso, mientras en este último caso el biólogo analiza normalmente "un único individuo, un único órgano, una única célula, una única parte de la célula" (Mayr, 1998a, p.89); en el caso de la biología evolutiva o integrista, el organismo debe ser siempre considerado en función de sus relaciones con el medio y con los otros organismos (Jacob, 1973, p.14).

Pero, concomitantemente e indisolublemente entrelazada con esa diferencia relativa a los objetivos cognitivos de un y otro dominio disciplinar, nos encontramos también con una diferencia relativa a los recursos conceptuales y metodológicos con los cuales esos objetivos son perseguidos. Así, mientras la biología evolutiva puede aún continuar operando, en cierto modo, con los conceptos y los métodos de la historia natural y con relativa prescindencia del saber físico y químico (Jacob, 1973, p.200), en el caso de la biología funcional nos encontramos con un conjunto de investigaciones que, en virtud de sus propios supuestos teóricos y en función de los problemas estudiados, da lugar a un discurso sobre lo viviente que, por su contenido conceptual y por sus procedimientos metodológicos, tiende a aproximarse progresivamente al discurso de la química y la física. 


\section{El programa reduccionista en biología funcional}

No serían éstas, entonces, quienes reducirían o absorberían a la biología funcional ampliando su área de aplicación; sino que sería la propia biología funcional la que, por su lógica inherente, tendería, activamente, a identificar su discurso con el de esas otras ciencias; y es en la propia práctica experimental en donde ese reduccionismo programático se torna más patente. Las causas próximas de las que se ocupa el biólogo funcional no son otra cosa que condiciones físicas y/o químicas cuya manipulación o producción experimental nos permite producir o variar la intensidad de efectos que también son observables y descriptibles en tanto que fenómenos físico-químicos. Es decir: en tanto que fenómenos registrables por instrumentos tales como termómetros, balanzas o reactivos.

Así, y como podemos leer en un manual de biología experimental - que, más que nada y como de costumbre, es un manual de biología funcional -, "la mayoría de los experimentos modernos en biología emplean instrumentos, herramientas o técnicas derivadas de las diversas ciencias físicas" (Norman, 1971, p.75); y eso lo confirmamos cuando leemos la lista de esas técnicas y la naturaleza de los instrumentos de los que las mismas se valen. Las más simples de esas técnicas son procesos de medida basados en recipientes volumétricos; pero enseguida pasamos a la calorimetría, la espectrofotometría, la cromatografía, los trazadores isotópicos, las mediciones eléctricas, la cristalografía, las técnicas e instrumentos para la medición de intercambios gaseosos, y la electroforesis.

Es decir: todo un arsenal de recursos para producir y registrar datos experimentales que se basan y se legitiman en el conocimiento físico y químico que, supuestamente, tenemos de las posibles interacciones entre ciertos instrumentos y los fenómenos orgánicos que queremos estudiar. Fenómenos que, de ese modo, serán registrados, identificados y considerados en virtud de sus dimensiones y propiedades físicas y químicas. Cabe decir, por eso, que ese repertorio de técnicas e instrumentos, en última instancia, sólo tiene sentido en el contexto de una estrategia de investigación cuyo supuesto fundamental es la presunción de que "no existe ningún carácter del organismo que no pueda, a fin de cuentas, ser descrito en términos de moléculas y de sus interacciones" (Jacob, 1973, p.15).

Puede decirse, por eso, que lo que verdaderamente define ese reduccionismo programático inherente a la biología funcional es la exigencia metodológica de que, para todo fenómeno, estructura o característica orgánica, siempre busquemos una descripción y una explicación de carácter fisiológico reducibles, ambas, a descripciones y explicaciones físico-químicas. La efectiva conquista de esa reducción se erige así en la meta que define la dirección, la 
agenda y el criterio para evaluar el éxito de las investigaciones desarrolladas en el contexto de la biología funcional.

Con todo, pese a que esa es la promesa de la biología molecular (Collins, Jegalian, 2000), para muchos cada día más próxima de ser plenamente cumplida, y aun con absoluta prescindencia de lo que pueda venir a decirse de la biología evolutiva, es muy posible que esta imagen reduccionista de la biología funcional sea objetada por tres tipos de razones que conviene que tratemos separadamente. Unas son razones que llamaremos lógicas, otras son razones que denominaremos teóricas y otras son razones que pueden ser caracterizadas como históricas. Puede hacerse converger, sin embargo, las tres líneas de críticas en un mismo punto: la idea según la cual el principal objetivo experimental del biólogo funcional es "aislar los constituyentes de un ser vivo" encontrando las condiciones que permitan su estudio "en el tubo de ensayo" (Jacob, 1973, p.15).

De ese modo, nos dice Jacob (1973, p.15), “variando estas condiciones, repitiendo los experimentos, precisando cada parámetro", el biólogo funcional conseguiría "dominar el sistema y eliminar sus variables". El punto de partida del trabajo experimental sería siempre, y sin ninguna duda, la complejidad del viviente individual, pero su meta sería precisamente la de descomponer esa complejidad y analizar sus elementos "con el ideal de pureza y certeza que representan las experiencias de la física y la química" (p.15). Así, siguiendo ese procedimiento analítico, concuerda Mayr (1998a, p.89), se puede realizar en biología "el ideal de un experimento puramente físico o químico".

Con todo, y he ahí la primera línea de objeciones que se puede presentar ante este modo de ver la biología funcional, "no todo lo que adviene a un organismo en el laboratorio es una realidad biológica" (Merleau-Ponty, 1953, p.215); es decir: no cualquier intervención experimental sobre un organismo será biológicamente relevante. Si "no se trata de hacer física en el ser viviente, sino la física del ser viviente" (p.215); los fenómenos orgánicos nos interesarán en tanto contribuyen, en el estado normal, o conspiran, en el estado patológico, a cierto resultado que, desde su planteo, nuestro análisis privilegia: la constitución y la preservación del propio organismo individual.

Sin ese interés, sin esa perspectiva que privilegia y recorta la constitución y la preservación del organismo individual como foco de convergencia de todas las series causales analizadas, no hay fisiología ni biología funcional en general. Esta disciplina, podemos decir, supone siempre en sus análisis una idea de estado privilegiado y limita sus análisis a mostrar cómo un determinado fenómeno orgánico interviene causalmente en la producción de ese estado (Goldstein, 1951, p.340); y era a eso a lo que tan claramente 
Claude Bernard apuntaba cuando en la Introduction a l étude de la médecine experiméntale nos decía que:

El fisiólogo y el médico no deben olvidar jamás que el ser vivo forma un organismo y una individualidad. El físico y el químico no pueden colocarse fuera del universo, estudian los cuerpos y los fenómenos aisladamente, en sí mismos, sin estar obligados a remitirlos necesariamente al conjunto de la naturaleza. Pero el fisiólogo, por el contrario, encontrándose ubicado fuera del organismo animal del cual ve el conjunto, debe preocuparse por la armonía de ese conjunto al mismo tiempo en que intenta penetrar en su interior para comprender el mecanismo de cada una de sus partes. De ahí resulta que, mientras el físico o el químico pueden negar toda idea de causas finales en los hechos que observan; el fisiólogo es llevado a admitir una finalidad armónica y preestablecida en los cuerpos organizados cuyas acciones parciales son todas solidarias y generadoras las unas de las otras. Es necesario reconocer, por eso, que si se descompone el organismo viviente aislando las diferentes partes, es sólo para facilitar el análisis experimental, y no para concebir esas partes aisladamente. En efecto, cuando se quiere dar a una propiedad fisiológica su valor y su verdadera significación, siempre es necesario remitirse al conjunto y no sacar ninguna conclusión definitiva si no es en relación a sus efectos en relación a ese conjunto. (Bernard, 1984, p.137)

"El agrupamiento de los fenómenos vitales en funciones", nos explica incluso Bernard (1878, p.340), "es la expresión de ese pensamiento". Una función no es otra cosa que "una serie de actos o de fenómenos agrupados, armonizados, en vistas a un resultado determinado"; y, si bien, para la ejecución de dicha función concurren "las actividades de una multitud de elementos anatómicos", ella no puede ser reducida a la "suma brutal de las actividades elementales de células yuxtapuestas" (p.370). Lejos de eso, para individualizar una función, para que quepa describir un conjunto de actividades orgánicas como cumpliendo una función, debemos considerarlas como "armonizadas, concertadas, de manera a concurrir en un resultado común" (p.370).

Así, y como más tarde lo haría notar otra vez Merleau-Ponty (1953, p.215): "un análisis molecular total disolvería la estructura de las funciones y del organismo en la masa indivisa de las reacciones físicas y químicas triviales". Por eso, "para hacer reaparecer, a partir de ellas, un organismo viviente", nos decía este autor, hay que reconsiderar a esas reacciones eligiendo "los puntos de vista desde donde ciertos conjuntos reciben una significación común, y aparecen, por ejemplo, como fenómenos de asimilación, como los componentes de una función de reproducción" (p.215); o, en definitiva, como momentos o pasos de cualquier otra función que nuestro análisis fisiológico esté procurando establecer. 
1 'Erotético' es lo relativo a las interrogaciones (erotemas).
La biología funcional parece, en efecto, suponer una perspectiva sobre los fenómenos orgánicos que no encuentran un análogo en la física o en la química; $\mathrm{y}$, por lo visto, la misma puede ser llamada, con toda justicia, de perspectiva funcional. Siendo que esa peculiaridad, como Rosemberg (1985, p.39ss) ha podido mostrar, se preserva, incluso, en el nivel de la biología molecular. Como en el ejemplo de la sección anterior, ante una secuencia de ADN cuya ocurrencia se verifique en el genoma de alguna especie de bacteria, el biólogo molecular habrá siempre de preguntarse por el papel causal, o función, que la proteína codificada por ese gen tiene en la constitución de tales organismos; y es ese sentido del término función que Craig Venter presuponía cuando dijo que cuarenta por ciento de los genes individualizados en el Proyecto Genoma Humano tienen aún una función desconocida (Gerhardt, 2001).

Hay, en efecto, una cierta distancia entre preguntarse por el simple efecto de un fenómeno y preguntarse por su función; y esa distancia tiene que ver con que, en este último caso, presumimos que ese fenómeno puede venir a tener un papel causal (Cummins, 1975, p.745ss; Ponce, 1987, p.105ss) en la consecución de cierto estado cuya realización define y ordena nuestro análisis. Pero, aunque ese interés pueda permitirnos hablar de una cierta autonomía erotética ${ }^{1}$ de la biología funcional frente a la física, creemos que el mismo no puede ser citado como un argumento contrario al reduccionismo enunciado por Jacob.

Es cierto que, al hablar sobre los procedimientos analíticos del biólogo funcional, Jacob no tuvo en su debida cuenta esa teleología intra-orgánica a la que aludía Bernard. Pero creemos que ese descuido obedece al simple hecho de que no era el modo de interrogación de la biología funcional lo que estaba en cuestión; sino el nivel ontológico en el cual debían buscarse, en última instancia, las respuestas para las preguntas formuladas en ese dominio de la biología. Y el hecho de que las tramas causales que convergen en la constitución del organismo individual sean siempre reconstruidas en vistas a ese resultado, no significa que tal reconstrucción no pueda, o no deba, ser llevada hasta el plano molecular. Después de todo, Jacob podría muy bien convenir con Maturana y Varela (1994, p.18) en la idea de que los organismos no son más que sistemas autopoiéticos moleculares; es decir: sistemas físicos capaces de producir y preservar su propia organización (p.69). Y eso sería un buen argumento para no cejar en nuestros esfuerzos por elucidar los mecanismos moleculares que materializan esa autopoiesis (p.68).

Pero, aunque pueda decirse que la perspectiva funcional no invalida la prosecución del programa reduccionista; puede formularse en contra de este una segunda objeción vinculada con su viabilidad: tal es el caso de las objeciones teóricas que han sido planteadas por autores como Walter Elsasser (1998) y Jean Hamburger (1986). 
Según esta línea de argumentación, el programa reduccionista podría estar proponiendo, por lo menos en algunos campos como el de la biología del desarrollo, desafíos que escaparían a nuestras posibilidades cognitivas. No se trata, claro, de poner en duda que los fenómenos orgánicos sean otra cosa que fenómenos moleculares; sino de alertar sobre la complejidad computacional involucrada en cualquier tentativa de explicar fenómenos fisiológicos complejos a partir de interacciones moleculares. Las variables a considerar y las posibles interacciones entre las mismas son tantas y tan intrincadas que parecen estar más allá de los límites matemáticos de lo computable (Simon, 1996, p.172).

Por eso, se dice, es mejor encarar ciertos fenómenos orgánicos siguiendo estrategias experimentales clásicas que, sin llegar a operar en el plano molecular, pueden, de todos modos, permitirnos un control y un conocimiento mucho más significativo de los mismos. Después de todo, desde Claude Bernard en adelante, desde el nacimiento mismo de su disciplina, el biólogo funcional piensa experimentalmente (Bergson, 1938, p.230); es decir: piensa los fenómenos orgánicos en la medida en que los analiza, controla y manipula experimentalmente. En su ciencia, vínculos causales o conceptos que no puedan ser plasmados o discriminados experimentalmente no tienen ningún espacio; y eso también vale para el propio programa reduccionista. Si los fenómenos biológicos han de ser considerados realmente, en la efectiva práctica científica, como fenómenos físicos y químicos, eso tiene que palparse y ejecutarse en los procedimientos experimentales; y lo que los argumentos antireduccionistas a la Elsasser vienen a decirnos es que, por lo menos para cierto tipo de fenómenos, eso es, a priori, imposible. Y no necesitamos volver a citar a Peter Medawar (1969) para recordar el pobre destino que les aguarda, en la historia de las ciencias, a los programas inviables.

Pero he ahí, justamente, la principal debilidad de estos argumentos: ante la obvia constatación de que ciertos fenómenos biológicos son más complejos de lo que parecía y ante las dificultades surgidas en las sucesivas tentativas de analizar los mismos desde una perspectiva puramente molecular, se argumenta, sobre la base de consideraciones matemáticas, a priori, que esas dificultades son infranqueables y que cualquier tentativa futura está destinada al fracaso. Lo cierto, sin embargo, es que, pese a esas dificultades, el programa sigue en marcha: la laboriosa búsqueda y el fatigoso mapeamiento de las intrincadas filigranas moleculares en las que están tramados los más complejos fenómenos orgánicos continúa; y, aquí y allá, se obtienen resultados, siempre parciales, casi ínfimos, pero efectivos y acumulables (Rosemberg, 2000).

El programa reduccionista, en definitiva, parece ofrecer más oportunidades concretas para el desarrollo de la investigación que 
los límites matemáticos postulados por algunos; y esa fertilidad heurística, esa capacidad de mantener abierto el campo de lo posible de indagar multiplicando rompecabezas, es fundamental en la historia de la ciencia (Chalmers, 1979). La ciencia es una actividad práctica y los científicos siempre se inclinan por aquellas ideas que los pueden mantener ocupados (Gould, 1995, p.358ss); y ese no parece ser el caso del holismo a la Elsasser.

Con todo, puede todavía objetarse que una cosa es decir que el programa molecular se enfrenta con límites insuperables y otra cosa muy distinta es afirmar que la reducción de todos los fenómenos orgánicos a fenómenos moleculares sea, realmente, el norte que guía todo el desarrollo de la biología funcional. Es que, sin apelar al non plus ultra de Elsasser, podemos todavía limitarnos a decir que quizá Jacob se equivoque al suponer que toda la biología funcional tienda a su propia molecularización. Nadie dudaría, es cierto, de llamar a esta tendencia de hegemónica (Kitcher, 1999; Lewontin, 2000); pero eso no implica negar la existencia de investigaciones que, aun siguiendo procedimientos más próximos a los de la fisiología y la embriología tradicional, continúan produciendo conocimientos novedosos y significativos. El modo de entender la biología funcional que Jacob nos presenta podría ser considerado como una simplificación histórica: no todos los caminos de esa disciplina parecen conducir a la biología molecular.

De hecho, los actuales desarrollos experimentales sobre clonación, aun cuando estén ciertamente imbuidos e instruidos por conocimientos sobre los componentes moleculares de las células, no por eso deben dejar de ser considerados como la continuación de un programa de ingeniería celular cuyas líneas generales fueron trazadas independientemente de la biología molecular. Las técnicas experimentales allí desarrolladas permiten, por otra parte, un control y una manipulación de ciertos procesos celulares cuyos fundamentos moleculares no son plenamente conocidos; y esto puede estar indicándonos la factibilidad y la fertilidad de programas de investigación que operando sobre niveles superiores de organización superior, como pueden serlo las células, pero también tejidos y órganos, no se demoren en la elucidación de los mecanismos moleculares sobre los que los mismos están montados.

Con todo, ante las dificultades y fracasos que siempre surgen y surgirán en esos dominios de investigación, nadie dudaría en suponer que la clave de las variables ocultas que vengan a desbaratar predicciones y experimentos podría ser encontrada en la estructura molecular de las células. En un momento u otro, estos programas de investigación que por razones pragmáticas puedan desarrollarse con relativa autonomía de la biología molecular, irán al encuentro de ella: para explicar o superar sus fracasos, pero también para fundamentar y explicar sus posibles éxitos. Y no se trata aquí de 
arriesgar profecías; sino de no pasar por alto que toda la experimentación en biología funcional, desde Claude Bernard en adelante, supone una intervención física y química sobre lo viviente.

En estos dominios, el biólogo puede pensar fisiológica o celularmente, pero actúa físicamente; y es por eso que, en última instancia, sólo en un descenso a la estructura molecular de lo viviente habrá de encontrar el fundamento y la explicación de los resultados que obtenga con sus intervenciones experimentales sobre el orden orgánico. Aunque en la práctica y coyunturalmente puedan subsistir programas no-moleculares en biología funcional; su propia razón de existir y su propia legitimidad depende de que se considere a los organismos como estructuras físicas. Para la biología funcional, el reduccionismo ontológico es más que una simple convicción metafísica: la sumisión del orden orgánico al orden físico constituye su propia condición de posibilidad. Sin ella, el proyecto experimental formulado por Claude Bernard (1984, p.144 -145) sería ilegítimo.

Pero esa condición de posibilidad define también un límite y un criterio último de legitimidad para toda explicación que pueda darse de un fenómeno orgánico: la misma, por lo menos en principio, debe ser físicamente justificable. La biología funcional cae bajo la jurisdicción teórica de la física y ésta se transforma en la última instancia a la cual podemos remitirnos ante cualquier conflicto irresuelto entre explicaciones biológicas alternativas. Así, en dominios como la fisiología o la embriología, la reducción de un enunciado o una explicación biológica a un enunciado o explicación física, aunque no siempre se busque sistemáticamente, se convierte en el criterio último de legitimación de cualquier resultado particular. La tesis de que la biología funcional es reductible en última instancia a la física tal vez deba ser considerada y defendida en sentido jurídico: la física rige esa disciplina como un tribunal de última apelación rige un dominio cualquiera de la actividad humana.

Podemos decir, entonces, que la jurisdicción del reduccionismo programático se extiende, necesariamente, a todos los fenómenos biológicos en tanto y en cuanto los mismos sean descriptos en términos físicos y registrados por instrumentos físicos de observación y medición como aquellos que, según decíamos más arriba, se usan en la práctica experimental de la biología funcional. Si no aceptásemos esa extensión estaríamos afirmando que existen fenómenos físicos para los cuales no hay explicación física posible. Es decir: estaríamos hablando de fenómenos registrados por esos aparatos e instrumentos para los cuales no habría, sin embargo, una explicación física para dar.

Lo que todavía debe discutirse, sin embargo, es si las únicas descripciones relevantes de un fenómeno biológico son aquellas 
pasibles de ser convertidas o sustituidas por descripciones que nos presenten a tales fenómenos como meros eventos físicos; o, si por el contrario, existen descripciones que, siendo biológicamente relevantes, no pueden ser, por principio, traducidas en un lenguaje físico; y es aquí en donde llegamos al límite que la biología evolutiva parece plantearle a ese reduccionismo programático. El lenguaje de la física no sólo no parece adecuado para describir los fenómenos que esta última estudia; sino que tampoco parece adecuado para plantear y dirimir los problemas que allí se plantean.

Pero no se trata aquí de incurrir en la postulación de fuerzas o fenómenos ajenos o contrarios a las leyes físicas que guiarían la historia de lo viviente; sino de no pasar por alto dos cuestiones que nos parecen fundamentales: una de ellas es la relativa al tipo de predicados que se utilizan en el discurso de la biología evolutiva; la otra es la relativa a la naturaleza de las explicaciones darwinianas y al carácter de las preguntas que estas responden. La primera cuestión la abordaremos a continuación a partir de un análisis de los predicados y de los procedimientos experimentales propios de la genética de poblaciones. La segunda, por su parte, será discutida en la última sección del trabajo cuando mostremos la diferencia de objetivo explanatorio que existe entre una explicación física y el tipo de explicación seleccional propio de la biología evolutiva.

\section{Los predicados poblacionales}

La genética de poblaciones, que el propio Mayr (1998b, p.137) reconoce como un capítulo de la biología evolutiva, es un dominio disciplinar que no sólo alcanzó un nivel de formalización que puede recordar a la física; sino que es también allí en donde Dobzhanky y otros investigadores pudieron superar el hiato entre lo formal y lo empírico por una vía rigurosamente experimental (Gayon, 1992, p.379). En los modelos matemáticos propios de esta disciplina, "el espacio evolutivo es definido por un campo de frecuencias génicas" (p.335); y, en el marco de ese teatro, el drama evolutivo es representado como una secuencia de cambios en esas frecuencias (Mayr, 1998a, p.639) cuyas causas son factores como mutaciones, migraciones, selección natural y deriva genética. Siendo ese mismo rigor matemático lo que permite utilizar las 'cajas' o 'jaulas de poblaciones' para efectuar experimentos que, con toda justicia, pueden ser considerados como genuinas abstracciones materiales.

Estas jaulas, también llamadas demómetros, son simples cajas de vidrio en donde una población de Drosophila melanogaster, para usar el ejemplo típico, puede desarrollarse y ser, tanto observada en condiciones ideales de aislamiento, cuanto sometida a diversas intervenciones experimentales. Siendo también viable la creación de diferentes poblaciones control que, aisladas en cajas semejantes, 
2 "La eficacia biológica darwiniana, también denominada 'valor selectivo o adaptativo y simbolizada generalmente como $w$, es más una medida relativa que absoluta. Si los portadores de un genotipo transmiten sus genes a la siguiente generación a una tasa que podemos designar como la unidad $\left(W^{\prime}=1\right)$, los portadores de otro genotipo en la misma población pueden transmitir sus genes con una tasa inferior o superior, $W^{\prime \prime}=1-\mathrm{S}$ o bien $1+\mathrm{S}$. El valor de $\mathrm{S}$ es el coeficiente de selección"

(Dobzhansky et al. 1980, p.102). podían ser objeto de observaciones y manipulaciones análogas De un modo casi trivial y ciertamente muy económico, estas jaulas permiten superar el obstáculo que representa la escala espacial y temporal de ciertos fenómenos evolutivos para su estudio experimental. Con todo, la simpleza técnica y la austeridad de este dispositivo experimental no pueden hacernos perder de vista su relevancia epistemológica.

Es que, como afirma Gayon (1992, p.383), "las jaulas de poblaciones han sido en definitiva a la genética evolutiva lo que el plano inclinado de Galileo fue para el estudio de la caída de los cuerpos. En una jaula de población, la selección natural está ahí toda entera, como la ley de caída de los cuerpos está en el movimiento de la bola que rueda". Pero, al igual que la caída de los cuerpos en el experimento del plano inclinado, la selección "está ahí substraída a lo que su naturaleza tiene de recalcitrantemente autónomo e inasible" (p.384). Allí, la materialidad siempre díscola del fenómeno natural está técnicamente sometida al rigor del formalismo matemático; y es por la mediación de tales formalismos que las condiciones iniciales de esos experimentos pueden ser consideradas como magnitudes que, articulándose en un paralelogramo de fuerzas, producen una resultante numéricamente determinable a partir de ellas.

Sin los modelos matemáticos de la genética teórica de poblaciones, esas jaulas no hubiesen sido posibles: hubiesen sido meros corrales de vidrio y madera, aptos para criar moscas, pero en los cuales poco hubiese habido para calcular. Es gracias al Principio de HardyWeimberg, y a todas las consecuencias que de él extrajeron los teóricos de la genética de poblaciones, que las frecuencias en que se dan los genes dentro de las poblaciones que habiten en esas cajas y la velocidad (esto es: cantidad de generaciones) en que las mismas varían, se transforman en magnitudes vinculadas, según relaciones matemáticas constantes, con el índice de eficacia biológica de cada uno de los genotipos allí presentes. ${ }^{2}$

Para ilustrar lo que estamos diciendo cabría imaginarnos un ejemplo muy simple de experimento que podría ser realizado sobre una población experimental de Drosophila melanogaster convenientemente confinada en una de estas jaulas. Podemos pensar, concretamente, en un experimento donde, dado el conocimiento de las proporciones de ciertos genes alelos, la alteración graduada de la 'eficacia biológica' $[w]$ de las tres diferentes combinaciones genotípicas a la que los mismos dan lugar - que para fines de nuestro ejemplo vale pensar como inicialmente idénticas - nos permita calcular cómo será la proporción de esos alelos en la generación posterior a esa modificación.

Así, si la combinación de menor eficacia biológica es la del homocigoto recesivo, y la del heterocigoto es igual o menor a la del homocigoto dominante, sería posible incluso calcular cuántas 
generaciones deberán pasar para que, dada la actual diferencia en $w$, el alelo recesivo acabe siendo desplazado. Pudiéndose, incluso, calcular y eventualmente producir la modificación que cabría introducir en los valores de $w$ para, de ese modo, acelerar, retrazar $\mathrm{o}$, llegado un punto, revertir ese proceso con mayor o menor velocidad.

La genética teórica de poblaciones nos permite pensar los fenómenos evolutivos como constituyendo un sistema de magnitudes vinculadas según relaciones matemáticas constantes; $\mathrm{y}$, en base a ella, la genética experimental de poblaciones nos permite manipular esas magnitudes de forma tal que las modificaciones que nosotros introducimos generen cambios controlables y calculables en otras magnitudes. Si el objetivo de toda ciencia experimental es establecer, como Claude Bernard (1984, p.93) pretendía, una correlación constante y asimétrica entre dos magnitudes $x$ e $y$ de forma tal que, controlando o graduando a $x$ consigamos determinar o graduar el valor de $y$; entonces deberemos concluir que la genética de poblaciones posee un conocimiento y un control experimental de los fenómenos evolutivos muy semejante a aquel que se puede acceder en el dominio de la biología funcional con relación a los fenómenos fisiológicos.

Sin embargo, y he ahí la diferencia que nos interesa mostrar, ese control experimental matemáticamente graduado se ejerce allí sobre variables y magnitudes que guardan algunas diferencias significativas con aquellas sobre las que se opera en el campo de la biología funcional. Si comparamos los experimentos hechos en genética de poblaciones con aquellos que son hechos en cualquier dominio de la biología funcional, veremos que una primera diferencia, que no por obvia es menos importante, reside en el hecho de que los fenómenos estudiados en el primer caso sólo se registran en el plano poblacional.

Una proporción entre alelos, un cambio en la frecuencia o en la eficacia biológica de algún gen, procesos migratorios o de deriva genética, etc., son todos fenómenos que, a diferencia de aquellos estudiados por la fisiología y la biología del desarrollo, sólo pueden señalarse y describirse en el marco de una población. Ninguno de ellos, y esto sí que es una 'verdad de Perogrullo', puede ser constado en un organismo particular. En cambio, un proceso celular, un fenómeno embriológico, una reacción hormonal o nerviosa son todas cosas que pueden ser apuntadas y estudiadas en el organismo individual; y no importa aquí si esos fenómenos son analizados en el nivel molecular o en niveles más complejos de organización.

Es cierto, de todos modos, que, en algunos casos, la naturaleza del fenómeno estudiado o, en todo caso, la naturaleza de los propios organismos en cuyo seno tal fenómeno ocurriría, nos obliga a trabajar sobre grupos y no sobre individuos aislados. Así ocurriría, 
por ejemplo, en un estudio sobre la absorción o liberación de una sustancia química cualquiera, por parte de algún tipo particular de bacteria. El mismo se valdría, muy posiblemente, de un cultivo de estos microorganismos y el fenómeno se analizaría no en cada bacteria individual, cosa que podría llegar a ser técnicamente imposible, sino considerando al cultivo en su totalidad como siendo un único agente químico que absorbe o libera una sustancia. La idea, sin embargo, es que cada bacteria individual produce ese fenómeno y lo que se estaría observando o midiendo sería, por lo tanto, la sumatoria de esos fenómenos individuales. Es decir: la cantidad de sustancia liberada o absorbida por el cultivo sería la suma de lo que cada bacteria puede, en media, absorber o liberar; y, en principio, ese proceso de absorción o liberación podría ser descrito y apuntado en cada bacteria individual.

Algo semejante podría decirse, incluso, sobre un posible estudio relativo a las malformaciones que produciría un agente físico o químico cualquiera en las larvas de ciertas moscas. Este estudio sería hecho, con toda seguridad, no ya sobre una única larva sino sobre muchas; y estas larvas podrían ser criadas en una caja cuyas características físicas podrían no ser muy diferentes a las de un demómetro. Pero, aun así, las malformaciones serían apuntadas y descriptas sobre cada larva individual o sobre cada mosca adulta. Los ensayos clínicos sobre respuestas a medicamentos, a tratamientos o a dietas, entran, por lo tanto, dentro de esa categoría de experimentos fisiológicos colectivos.

Podría ocurrir, es cierto, que no todas las moscas de la especie estudiada tengan la misma propensión a desarrollar malformaciones. Entonces, si pudiésemos mostrar que esas diferencias obedecen a factores genéticos, cabría también estudiar el impacto que esa propensión tiene en la eficacia biológica de sus portadores; y en ese caso nuestro estudio pasaría a versar, ahora sí, sobre fenómenos poblacionales. Lo que en ese caso cambiaría, sin embargo, no es tanto la cantidad de los organismos afectados por el estudio sino el tipo de preguntas que en un caso y otro se plantean. Se trata, por decirlo de algún modo, de una diferencia epistemológica y no de una diferencia meramente técnica o cuantitativa.

Pero, si en estos últimos casos puede resultar relativamente fácil demostrar cuál es la diferencia entre la perspectiva poblacional y la perspectiva organicista o individual, no parece ocurrir lo mismo cuando consideramos estudios sobre cruzamientos como aquellos realizados por Morgan o por el propio Mendel. Nadie, es cierto, consideraría los trabajos de estos autores como resultados de la genética de poblaciones; pero puede no ser del todo sencillo explicar cuál es la diferencia que existe entre los cruzamientos entre moscas que Morgan hacía en sus botellas y los experimentos que se hacen en una jaula de poblaciones. 
La semejanza entre ambos procedimientos, por el contrario, parece obvia: podría parecer que entre una botella de Morgan y una jaula de poblaciones no hay más que una diferencia de tamaño. De hecho, un experimento de cruzamiento entre moscas, por simple que sea, no sólo precisa de un macho y de una hembra; sino que, por lo común, sólo se podrá obtener resultados significativos en la segunda generación. Además, esos resultados sólo serán inteligibles en la medida en que se considera y se compara la totalidad de los descendientes.

¿No estamos aquí, entonces, también frente a fenómenos de índole poblacional? ¿No son éstos también, por acaso, fenómenos que, como dijimos más arriba, tampoco pueden ser descriptos o apuntados en el organismo individual sino que sólo se registran y producen en el plano poblacional?

Claro, una pareja de moscas y sus descendientes no constituyen en sentido estricto una población: ningún biólogo lo consideraría así y no deja de ser significativo que predicados definitorios de una población tales como densidad, razón entre sexos, tasas de nacimientos y muertes, etc., no sean relevantes para describir los clanes de moscas analizados por Morgan. Es innecesario decir, por otra parte, que tampoco tendría sentido apuntar o negar la ocurrencia de fenómenos migratorios o de presiones selectivas que pudiesen afectar a tales grupos. Y esto no es una cuestión empírica sino conceptual: por definición, y contrariamente a lo que ocurre con una población, el devenir de estos clanes morganianos nunca podrían ser perturbados por un proceso de migración.

Pero, a parte de esas consideraciones, de por sí reveladoras, puede apuntarse también el hecho de que los padrones de distribución de caracteres producidos por los experimentos de Morgan son indicativos de fenómenos que, lejos de ocurrir en el plano poblacional, ocurren a nivel celular. Por eso se habla, con toda justicia, de una teoría cromosómica de la herencia. Los experimentos de cruzamiento acabaron siendo, al fin y al cabo, un recurso metodológico, el único disponible, para vincular caracteres hereditarios con estructuras cromosómicas específicas (Jacob, 2000, p.56).

Así, las conclusiones del célebre artículo en el cual Morgan (1910, p.122) presenta los experimentos sobre drosophila que hemos referido, versan sobre las características del óvulo y del espermatozoide que habrían estado involucrados en la generación de aquel macho mutante de ojos blancos. Sólo el microscopio apuntado a los convenientes cromosomas gigantes de las glándulas salivares de la drosophila, y no las jaulas de poblaciones, podía respaldar sus conclusiones (Rostand, 1985, p.185). Fomentando o impidiendo el cruzamiento entre ciertas moscas, lo que Morgan hacía era manipular, indirectamente, fenómenos celulares; es decir: variables de tipo fisiológico que, eventualmente, podrían también 
llegar a ser manipuladas de forma directa operando sobre las estructuras cromosómicas allí involucradas (Jacob, 1973, p.247; Rostand, 1985, p.184).

Al fin y al cabo, es por medio de esos procedimientos que Morgan "pone en evidencia la recombinación genética por traspaso de fragmentos entre cromosomas"; "muestra que la cantidad de recombinación mide la distancia sobre el cromosoma"; e incluso "establece la distribución de los genes sobre un cromosoma" (Jacob, 2000, p.54). Nada de eso ocurre, sin embargo, con los experimentos hechos en cajas de poblaciones. Las intervenciones que allí se realizan y los resultados que allí se obtienen se inscriben siempre y necesariamente en el plano poblacional: no tendría sentido, no sería pensable, que los mismos pudiesen ser substituidos y validados por observaciones y experimentos fisiológicos.

Mientras los resultados de Morgan no podían dejar de suscitar interrogantes sobre la fisiología de los genes y sobre su naturaleza química (Jacob, 2000, p.56), no ocurrió lo mismo con los resultados de la genética experimental de poblaciones: no hay referente fisiológico posible para conceptos como eficacia biológica o frecuencia génica y, por lo tanto, no cabe una fundamentación fisiológica de los resultados que involucren esas categorías. Estos conceptos, insistimos en lo obvio, sólo pueden ser usados para describir poblaciones y sólo pueden designar variables poblacionales; jamás variables fisiológicas u orgánicas. El propio concepto de gen de la genética de poblaciones no tiene por qué tener un referente fisiológico específico; y, por eso, hoy su suerte no está atada a los avatares y dificultades del concepto de gen como secuencia de ADN.

Pero, indisolublemente vinculado con la naturaleza poblacional de las variables sobre las que se opera en la genética experimental de poblaciones, está también el hecho de que esas variables no puedan ser físicas o químicamente definidas o descriptas. A dife-rencia de lo que ocurre con las variables fisiológicas que siempre pueden ser analizadas, por lo menos parcialmente, en términos físico-químicos, nunca podremos encontrar predicados o magnitudes físicoquímicas que realmente nos sirvan, que sean cogniti-vamente relevantes, para describir fenómenos migratorios, para medir la eficacia biológica de un alelo o para calcular la razón entre sexos en el seno de una población.

Las poblaciones y sus avatares no pueden, en definitiva, ser descriptos nunca en términos físicos o químicos, y esto nos indica que no se trata de sistemas físicos. Las poblaciones son sistemas irreductiblemente biológicos. Los organismos que las componen, es cierto, pueden ser considerados como sistemas complejos de moléculas sometidos a interacciones físicas entre ellos y con el entorno en general; pero los predicados que los biólogos usan para describir esas poblaciones no aluden, ni precisan aludir, siquiera 
indirectamente, a esa composición molecular y a esas interacciones. Una población, en resumen, es algo más que muchos organismos juntos. Una población, dirían algunos, es un sistema que posee propiedades emergentes a las propiedades de los organismos.

Pero atención: decir que una población no es sistema físico no constituye una incursión en alguna rancia y trasnochada 'metafísica de lo viviente'. Se trata, por el contrario, de simplemente reconocer que los predicados y las variables poblacionales no son ni predicados que pertenezcan al lenguaje de la física, ni variables cuyos estados puedan ser descriptos en los términos de ese lenguaje; y lo que vale para esos predicados y esas variables vale también para las intervenciones experimentales que sobre ellos podemos hacer.

Las mismas no pueden ser, ni caracterizadas en términos físicos ni mensuradas en base a magnitudes de esa índole. Nuestras intervenciones experimentales sobre las poblaciones sólo pueden, por eso, ser caracterizadas y proyectadas en términos biológicos; $y$ es en ese sentido que cabe decir que se trata de intervenciones biológicas y no de intervenciones físicas o químicas como las que se realizan en el dominio de la biología funcional. Si en la fisiología experimental se puede hablar de la utilización de 'bisturís químicos' (Grmek, 1991, p.141ss), en la genética experimental de poblaciones tenemos que hablar de 'bisturís biológicos'. Sólo que éstos no afectan a los tejidos orgánicos sino a la composición de las propias poblaciones.

Es cierto, no hay cambio o diferencia que no suponga un cambio o una diferencia física; nada ocurre en este mundo si físicamente todo sigue igual. Pero, sin cuestionar esa saludable certeza fisicalista, se puede aun reconocer que cuando se altera la temperatura de una jaula de población, cuando se rocía a sus habitantes con alguna sustancia química o se los separa con una lámina de vidrio, o cuando se 'importan' desde otra caja moscas de una raza geográfica diferente a la original, se está haciendo algo cuya caracterización física es prácticamente irrelevante para los objetivos cognitivos de la genética de poblaciones. Todas esas intervenciones físicas sólo tendrán valor experimental dentro de ese dominio disciplinar en la medida en que puedan ser caracterizadas como manipulaciones de variables específicamente poblacionales.

Un cambio de temperatura puede ser un recurso para alterar la eficacia biológica de ciertos alelos. Una mampara de vidrio o de madera puede ser un medio para producir aislamiento geográfico. Abrir la caja y soltar dentro moscas de otra proveniencia puede ser un medio para alterar el pool genético de la población inicial. Pero, en todos los casos, lo que importa es el fenómeno biológico desencadenado o la variable biológica alterada; y lo que se quiere conocer, lo que se quiere mensurar, no es el impacto de la intervención física sobre ese fenómeno o sobre esa variable que se 
3 En Caponi (2003) podrá encontrarse una versión ampliada de los argumentos presentados en esta sección. altera, sino el impacto que la alteración de ese fenómeno o esa variable tienen sobre otros fenómenos $u$ otras variables poblacionales. Y esto con independencia de la técnica de observación que se utilice para conocer o medir la magnitud de ese impacto.

En los experimentos de biología funcional, podríamos decir, se manipulan y controlan variables físico-químicas que afectan esos sistemas físicos complejos que son los organismos individuales. En los experimentos de biología evolutiva, en cambio, se manipulan y controlan variables biológicas y, tal vez geográficas (como, por ejemplo, simples factores de aislamiento), que afectan esos sistemas irreductiblemente biológicos que son las poblaciones. Unos, digamos, son un tipo muy particular de experimento físico; los otros, en cambio, son experimentos de una índole diferente: son experimentos poblacionales.

Notemos, por otra parte, como esas diferencias entre variables fisiológicas y variables poblacionales son también relevantes para entender mejor la diferencia entre causas próximas y causas remotas. Las primeras son fenómenos física o químicamente descriptibles y capaces de actuar localmente sobre un organismo individual; las segundas son factores que actúan globalmente sobre una población y alteran su composición. La selección natural es, por eso, el ejemplo privilegiado de causación remota (Martínez, 1997, p.172-173): ella actúa sobre las poblaciones; pero esa acción no podría jamás ser considerada como una resultante o una suma del modo en que ese factor operaría sobre los individuos (p.136). Nada ni nadie podría nunca registrar la intensidad de la selección natural que opera sobre un organismo individual. De hecho, al intentar imaginar esa posibilidad nos colocamos en el borde del sin sentido: la gramática del concepto de selección natural no nos deja margen para cometer ese genuino abuso de lenguaje.

\section{De causas y razones ${ }^{3}$}

Se podría pensar, sin embargo, que las explicaciones darwininistas por causas remotas no son más que una suerte de descripción resumida, simplificada o condensada, de un vasto conjunto de fenómenos individuales, todos ellos de carácter puramente físico, cuyo efecto final es también un fenómeno descriptible en términos puramente físicos. Al fin de cuentas, se dirá, todos esos fenómenos son registrables por aparatos físicos de medición y nadie podría sostener que, en tanto tales, los mismos sean causados por alguna fuerza que no sea una fuerza física. Al final de cuentas, cuando decimos que una población de mariposas está siendo depredada por una población de pájaros y que esa depredación hace que algunas de esas mariposas se reproduzcan menos que otras, aludimos, de hecho, a fenómenos que pueden ser descriptos desde una 
perspectiva puramente física.Las mariposas y los pájaros son estructuras moleculares. Todos sus mecanismos fisiológicos, incluidos aquellos que están involucrados en la reproducción y el desarrollo pueden, en última instancia, ser descriptos y explicados en términos moleculares; y no cabe duda de que el vuelo de esos animales sobre una pradera es también un fenómeno físico como incluso lo es el impacto del pico de los pájaros sobre los cuerpos de las mariposas. E incluso, hasta la resultante de todo ese torbellino de eventos físicos, el cambio en la frecuencia de las diferentes variantes de mariposas, puede considerarse como un hecho pasible de descripción física. En la medida en que las variaciones de estructura obedecen a una cierta base molecular, podemos describir ese cambio en la frecuencia de las diferentes variantes como siendo un cambio en la frecuencia de ciertas estructuras moleculares dentro del sistema físico constituido por todos esos agregados de átomos que son las mariposas de esa población.

Con todo, aunque toda esa engorrosa y casi demencial descripción fuese factible, ella no podría sustituir una explicación darwiniana de por qué ciertas formas se tornaron más frecuentes que otras. Es que la reconstrucción de toda esa maraña de eventos físicos, aun explicándonos cómo algo ocurrió, todavía estaría dejando sin responder la pregunta que define el objetivo explanatorio de las explicaciones evolucionistas: ¿por qué P pudo resultar mejor que $\mathrm{R}$ en el contexto T? Es decir: la explicación darwinista debe indicar qué ventajas pudo representar una variante en relación a otras; y eso es lo mismo que formular un balance y una comparación de los costos y beneficios implicados por las diferentes formas alternativas.

La explicación física puede mostrarnos cómo se comportaron o actuaron ciertas estructuras pero nunca podrá decirnos bajo qué consideraciones una pudo resultar más ventajosa que otra: no hay traducción física para este tipo de preguntas y mal puede haber respuestas físicas para las mismas. Así, aunque una súperinteligencia laplaciana pudiese describir, predecir, y explicar físicamente la evolución de una población como si fuese una nube de moléculas; no por eso estarían siendo respondidas las preguntas que un biólogo darwinista se plantea cuando considera las estructuras orgánicas en términos adaptativos. Es que, en última instancia y más allá de cualquier otra consideración, la razón más clara que se puede alegar en contra de la idea de que la explicación darwinista sea un resumen o una simplificación de alguna compleja explicación física de los fenómenos evolutivos radica en el hecho de que las explicaciones darwinianas de la adaptación no responden a preguntas formulables desde una perspectiva física.

La explicación darwiniana no es, en sentido estricto, una explicación por causas eficientes de un evento ocurrido. Ella es, 
más bien, la explicación de una diferencia de frecuencia entre dos alternativas que, indicándonos una opción o una preferencia, nos dice por qué algo pudo ser mejor que otra cosa en un determinado contexto; y esto puede ser representado en este modelo general de la explicación seleccional:

\section{Explanans:}

La población $\mathrm{P}$ está sometida a la presión selectiva $\mathrm{S}$.

La estructura $X$ [presente en $P$ ] constituye una mejor respuesta a $S$ que su alternativa $Y$ [también presente en P].

\section{Explanandum:}

La incidencia de $X$ en $P$ es mayor que la de $Y$

En esta explicación, las presiones selectivas a las que está sometida una población no son consideradas como causas mecánicas de la retención de las estructuras adaptativas. La misma, como vemos, no apela, ni precisa apelar, a ningún enunciado nomológico que conecte presión selectiva y respuesta como si se tratase de una relación causal humeana. En lugar de mostrarnos una relación de causa-efecto, la explicación darwinista exhibe una ecuación de costo-beneficio. Es que, en el dominio de la biología evolutiva puede decirse, o bien que las cosas están donde están porque su presencia implicó, en algún momento, un beneficio mayor que el que hubiese implicado su ausencia, o bien que perduran porque perderlas implicaría más costos que retenerlas. Y esa diferencia, a menudo exigua, de costos o beneficios que favorece la difusión o la persistencia de alguna cosa no constituye la causa de esa cosa sino su razón de ser (Dennett, 1991, p.230; 1995, p.76).

Una razón, en definitiva, no es más que aquello que se puede dejar de ganar o dejar de perder haciendo o dejando de hacer alguna cosa; y es en ese sentido que podemos decir que la explicación darwinista, semejantemente a lo que ocurre con la explicación intencional propia de las ciencias humanas, es una explicación por razones antes que una explicación por causas. La descripción de las presiones selectivas a las que está sometida la población explica la retención de una estructura no por describir la causa eficiente que la produce sino por mostrar las razones de esa retención (Brandon, 1990, p.166); y no existe traducción física de nada semejante a una razón o a una diferencia entre costos y beneficios. La vida, podríamos decir, tiene razones que la física desconoce.

Por eso, una 'súper-física' como la postulada por Ilya Prigogine (1972, p.562) o por Brian Goodwin (1998, p.209) podría, tal vez, tornar irrelevantes las preguntas de la biología evolutiva transformando a la selección natural en una ilusión análoga a la navegación sobre rieles de los barcos de Disneylandia (Dennett, 2000, p.338). 
Pero tornar irrelevante o 'disolver' una pregunta no es lo mismo que responderla; y eso es una diferencia clave entre la relación que la biología funcional guarda con la física y la relación que, con esta última, guarda la biología evolutiva. Mientras, un análisis físico completo de los procesos que se integran en la autopoiesis orgánica constituiría la consumación de la biología funcional; la consumación de los programas de Goodwin o de Prigogine podría implicar, quizá, la clausura de la biología evolutiva al tornar sus preguntas irrelevantes.

Mientras la biología funcional marcha al encuentro de la física, la biología marcha en una dirección diferente; y esa dirección está pautada por un modo de interrogar los fenómenos que no pide respuestas que aludan a relaciones causales de carácter físico. Cuando dejamos de considerar un rasgo anatómico, fisiológico o comportamental como mero fenómeno bioquímico o como simple reacción hormonal o neuronal a ser explicada por causas inmediatas, y comenzamos a pensarlo como una estructura adaptativa resolutora de problemas, ese cambio no obedece, en contra de lo que Rosemberg (1994, p.102; 1999, p.28) afirma, a la desproporción entre la complejidad de los fenómenos en análisis y a las limitaciones de nuestro aparato cognitivo sino a un cambio en nuestro objetivo explanatorio.

Lo que queremos preguntar, lo que queremos saber, ya no es lo mismo; $y$, tal como lo ha sugerido en una feliz imagen Daniel Delouya (1994, p.53), una explicación molecular completa y aun 'laplacianamente' satisfactoria de los fenómenos orgánicos que ocurren al nivel poblacional estudiado por la biología evolutiva, podría dejar tantas preguntas interesantes sin responder como lo haría un análisis físico del funcionamiento y de las trayectorias de los ómnibus que unen Campinas a São Paulo con relación a nuestras posibles preguntas sobre el modo de funcionamiento de un sistema público de transportes. La más completa y poderosa 'física de lo viviente' no podría jamás relevarnos de su hermenéutica (Dennett, 1995, 212ss).

\section{BIBLIOGRAFÍA}

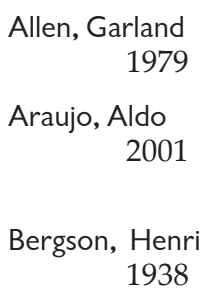

Naturalists and experimentalists: the genotype and the phenotype. Studies in History of Biology, Baltimore, v.3, p.179-209.

O salto qualitativo em Theodosius Dobzhansky: unindo as tradições naturalista e experimentalista. História, Ciências, Saúde - Manguinhos, Rio de Janeiro, v.8, n.3, p.713-726.

La pensée et le mouvant. Paris: PUF. 


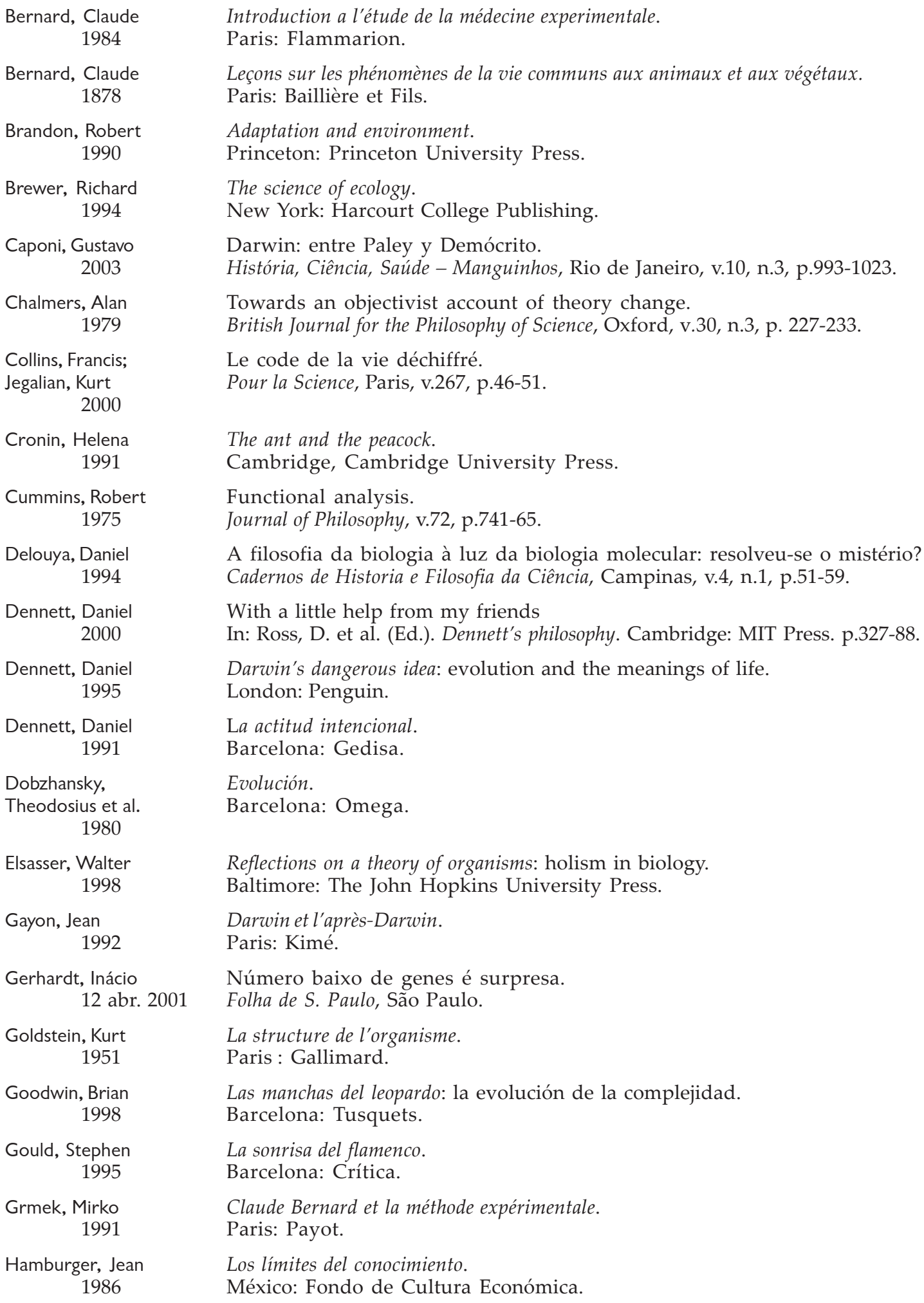




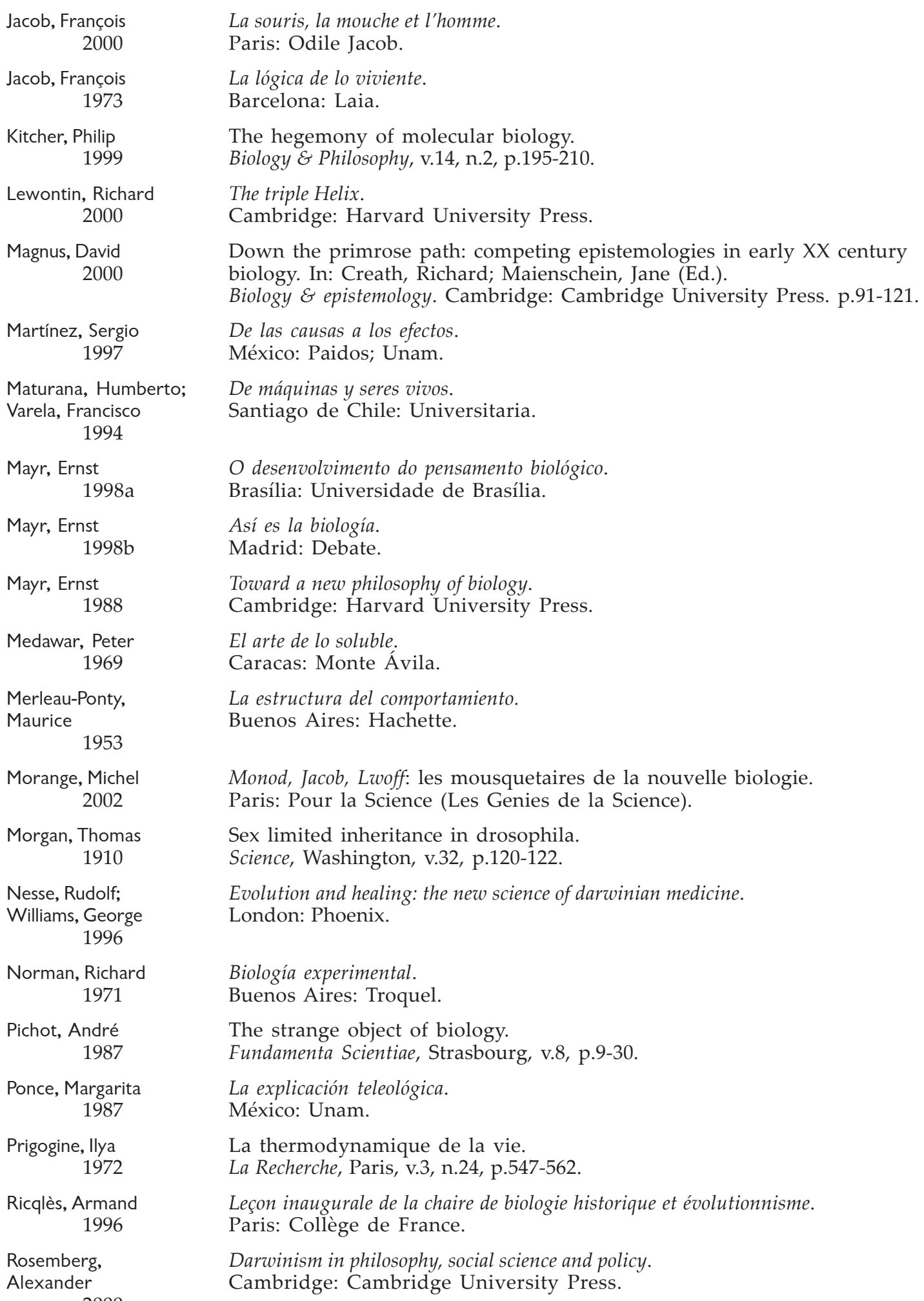

La souris, la mouche et l'homme.

Paris: Odile Jacob.

La lógica de lo viviente.

Barcelona: Laia.

The hegemony of molecular biology.

Biology \& Philosophy, v.14, n.2, p.195-210.

The triple Helix.

Cambridge: Harvard University Press.

Down the primrose path: competing epistemologies in early $\mathrm{XX}$ century biology. In: Creath, Richard; Maienschein, Jane (Ed.).

Biology \& epistemology. Cambridge: Cambridge University Press. p.91-121.

De las causas a los efectos.

México: Paidos; Unam.

De máquinas y seres vivos.

Santiago de Chile: Universitaria.

O desenvolvimento do pensamento biológico.

Brasília: Universidade de Brasília.

Así es la biología.

Madrid: Debate.

Toward a new philosophy of biology.

Cambridge: Harvard University Press.

El arte de lo soluble.

Caracas: Monte Ávila.

La estructura del comportamiento.

Buenos Aires: Hachette.

Monod, Jacob, Lwoff: les mousquetaires de la nouvelle biologie.

Paris: Pour la Science (Les Genies de la Science).

Sex limited inheritance in drosophila.

Science, Washington, v.32, p.120-122.

Evolution and healing: the new science of darwinian medicine.

London: Phoenix.

Biología experimental.

Buenos Aires: Troquel.

The strange object of biology.

Fundamenta Scientiae, Strasbourg, v.8, p.9-30.

La explicación teleológica.

México: Unam.

La thermodynamique de la vie.

La Recherche, Paris, v.3, n.24, p.547-562.

Leçon inaugurale de la chaire de biologie historique et évolutionnisme. Paris: Collège de France.

Darwinism in philosophy, social science and policy.

Cambridge: Cambridge University Press. 
Rosemberg,

Alexander

1999

Rosemberg

Alexander

1994

Rosemberg,

Alexander

1985

Rostand, Jean

1985

Simon, Herbert

1996

Simpson, George

Gaylord

1974

Sober, Elliot

1993
Les limites de la connaissance biologique.

Annales d'Histoire et Philosophie du Vivant, Paris, v.2, p.15-34.

Instrumental biology.

Chicago: The Univ. of Chicago Press.

The structure of biological science.

Cambridge: Cambridge University Press.

Introducción a la historia de la biología.

Madrid: Planeta.

The sciences of the artificial.

Cambridge: The MIT Press.

La biología y el hombre.

Buenos Aires: Pleamar.

The philosophy of biology.

Oxford: The Oxford University Press.

Recibido para publicación en marzo de 2005.

Aprobado para publicación en octubre de 2006. 